\title{
4-acetamido-TEMPO-mediated oxidation of wood chips and thermomechanical pulp in large scale
}

\author{
David Myja $^{\mathrm{a}}$, Eric Loranger ${ }^{\mathrm{a}}$ and Robert Lanouette ${ }^{\mathrm{a}}$ \\ ${ }^{a}$ Institut d'Innovations en Écomatériaux, Écoproduits et Écoénergies à base de biomasse, Université du \\ Québec à Trois-Rivières, P.O. Box 500, Trois-Rivières, Québec, Canada, G9A $5 H 7$ \\ Contact information: eric.loranger1@uqtr.ca
}

Declaration of interest: none.

\begin{abstract}
The TEMPO-mediated oxidation was mainly studied in laboratory scale and need to be scale-up for any future industrial implantation. With this objective, the oxidation was applied at several step in a thermomechanical pulp production system. Softwood chips were impregnated with a TEMPO mixture or treated in batch before refining, leading to a modification of pulp mechanical and optical properties. The TEMPO oxidation was also studied on softwood pulp with a usual batch oxidation, a high consistency treatment or by replacing the diluting water by a TEMPO oxidation medium during the secondary refining. Pulp from high consistency oxidation presented a significant energy potential gain. However, optical properties were severely affected and could not be totally recovered by a conventional hydrogen peroxide bleaching. The refiner was also used as a nanofiber producing apparatus for pulp with carboxylic group content higher than $1500 \mathrm{mmol} / \mathrm{kg}$. For this application, the refiner appeared to be a high efficiency dispersion system to produce significant amount of nanofibers at low energy consumption.
\end{abstract}

Keywords: 4-acetamido-TEMPO mediated oxidation, refiner system, softwood chips impregnation, high consistency softwood pulp treatment, hydrogen peroxide bleaching, nanofiber production

\section{Introduction}

The 2,2,6,6-tetramethylpiperidine-1-oxyl, sodium bromide and sodium hypochlorite (TEMPO/NaBr/NaOCl) system is a well know oxidation [1] which has gain interest in the last years [2]. This 
oxidation system was first used on cellulose and chitin [3] but it is nowadays applied to other material like thermomechanical pulp (TMP) [4] or non-wood resources [5]. The TEMPO-mediated oxidation is used for several application as paper reinforcement [6] or nanofibers production [7] with their large field of use [8, 9]. Several oxidation parameters were studied along the years $[10,11]$ and we already optimized reaction conditions on TMP at lab scale oxidation [12]. To further analyze oxidized pulp production using the TEMPO system, it was necessary to study the reaction scaling-up. Paquin et al. [13] have developed a sonoreactor to treat around half a kilogram of pulp at a time. However, to use this technology into an actual industrial production, new equipment must be implemented into the industrial plant.

In this work, we were looking to introduce the 4-acetamido-TEMPO-mediated oxidation at different stage of a usual thermomechanical pulp production plant. We used the oxidation mixture to impregnate wood chips before primary refining. We also replaced water during secondary refining by the reaction medium. We studied chips and primary pulp pretreatment too, in a large-scale batch or at high consistency on primary pulp. All those treatments were compared to classical refining of wood chips and primary pulp.

\section{Experimental}

\subsection{Material}

In this work, we treated two different raw materials. Softwood chips were purchased from Kruger S.E.C. (Trois-Rivières, Canada) and primary softwood thermomechanical pulp from White Birch/Papier Masson (Gatineau, Canada). 4-acetamido-TEMPO, sodium bromide and sodium hypochlorite were used as received respectively from Chemos, Thermo Fisher Scientific Chemicals Inc. and Sigma-Aldrich. Other chemicals were used for conventional hydrogen peroxide bleaching experiments. Hydrogen peroxide and sodium hydroxide were purchased from Thermo Fisher Scientific Chemicals Inc. while sodium silicate and diethylenetriaminepentaacetic acid (DTPA) were purchased from Sigma-Aldrich.

The refiner used in this work was a Valmet CD300 pilot refiner with a 12 inches single disc. Refining were made under atmospheric conditions with a $1 \mathrm{~L} / \mathrm{min}$ fluid flow. 


\subsection{Methods}

\subsubsection{Softwood chips treatments}

Softwood chips were refined according to three different procedures to observe two ways of oxidation implementation. Table 1 regroup treatments that have been done.

Table 1 Survey of softwood chips pretreatment and refining conditions

\begin{tabular}{|c|c|c|c|c|}
\hline Pulp name & Raw material & Pretreatment & Impregnation & Disc gap (mm) \\
\hline $\mathrm{C} 1$ & Softwood chip & / & Water & 1.0 \\
\hline $\mathrm{TC} 1$ & Softwood chip & l & $\begin{array}{c}\text { TEMPO mixture } \\
\text { TEMPO: } 0.45 \mathrm{mmol} / \mathrm{g} \\
\mathrm{NaBr:} 3.158 \mathrm{mmol} / \mathrm{g} \\
\mathrm{NaOCl}: 18 \mathrm{mmol} / \mathrm{g}\end{array}$ & 1.0 \\
\hline $\mathrm{C} 2-1$ & \multirow{4}{*}{$\mathrm{C} 1$} & \multirow{4}{*}{1} & \multirow{4}{*}{ l } & 0.60 \\
\hline $\mathrm{C} 2-2$ & & & & 0.50 \\
\hline $\mathrm{C} 2-3$ & & & & 0.40 \\
\hline $\mathrm{C} 2-4$ & & & & 0.30 \\
\hline TC2-1 & \multirow{4}{*}{ TC1 } & \multirow{4}{*}{ l } & \multirow{4}{*}{ l } & 0.50 \\
\hline TC2-2 & & & & 0.40 \\
\hline TC2-3 & & & & 0.30 \\
\hline TC2-4 & & & & 0.20 \\
\hline BTC-1 & & TEMPO oxidation $^{\mathrm{a}}$ & & 1.0 \\
\hline BTC-2 & Softwood chip & TEMPO: $0.45 \mathrm{mmol} / \mathrm{g}$ & 1 & 0.70 \\
\hline BTC-3 & & $\mathrm{NaOCl}: 18$ mmol/g & & 0.15 \\
\hline 10 & by & Myja & & \\
\hline
\end{tabular}

The first chips treatment was a regular primary refining at $1.0 \mathrm{~mm}$ disc gap previously impregnated with water at $90^{\circ} \mathrm{C}$. This pulp was called $\mathrm{C} 1$ from now on in this manuscript. A secondary refining of $\mathrm{C} 1$ was 
made at $0.60,0.50,0.40$ and $0.30 \mathrm{~mm}$ disc gap leading respectively to pulp $\mathrm{C} 2-1$ to $\mathrm{C} 2-4$. The second chips refining leading to pulp TC1 was the same as for $\mathrm{C} 1$ but instead of an impregnation with water, the TEMPO oxidation mixture was used. Chemicals amount used to make this solution were determined according to previous optimization done by Myja et al. [12] and are reported in Table 1. The secondary refining of TC1 was done with exactly the same conditions as for $\mathrm{C} 1$ and gave pulp TC2-1 to TC2-4. A last set of trial was performed using dislocated chips, oxidized in a large batch with the same elements as describe in Myja et al. work [12]. Table 1 regroup the chemicals amount for the reaction. After this treatment, chips were refined at 1.0, 0.70 and $0.15 \mathrm{~mm}$ disc gap. Obtained pulps were called BTC-1 to BTC-3. After each refining, pulps were washed, filtrated and stored at $6^{\circ} \mathrm{C}$ until analysis.

\subsubsection{Softwood thermomechanical pulp treatments}

Directly on a commercial softwood primary pulp, four different treatments were done. At the beginning, a usual secondary refining was done on the pulp at $0.60,0.50,0.45,0.40,0.35$ and $0.30 \mathrm{~mm}$ disc gap. Resulting pulps were respectively named P-1 to P-6. To get pulp TP-1 to TP-7, the water used during the refining was replaced by a TEMPO mixture. Chemicals amount was the same as used for chips, but the sodium hypochlorite quantity was adapted to maintain TEMPO and NaBr amount with a $1 \mathrm{~L} / \mathrm{min}$ flow during the refining. Exact chemicals amounts are reported in Table 2. As for the softwood chips, a TEMPO oxidation pretreatment was also carried on primary TMP softwood pulp with the same condition. Disc gap were fixed at 1.0, 0.50 and 0.15 leading to pulp BTP-1 to BTP-3. For the last set of trials, a high consistency (25\%) pretreatment was done on regular thermomechanical pulp before a secondary refining. TEMPO and sodium bromide amounts were the same as for the other treatments and the sodium hypochlorite quantity was fixed to get the $25 \%$ final consistency. The refining was performed at $1.00,0.50,0.40,0.30$ and $0.25 \mathrm{~mm}$ disc gap to have pulps HCTP-1 to HCTP-5. As made previously, all pulps were washed, filtrated and stored at $6^{\circ} \mathrm{C}$ until analysis. 
Table 2 Survey of softwood pulp pretreatment and refining conditions

\begin{tabular}{|c|c|c|c|}
\hline Pulp name & Pretreatment & Fluid used while refining & Disc gap $(\mathrm{mm})$ \\
\hline $\mathrm{P}-1$ & \multirow{4}{*}{ / } & \multirow{4}{*}{ Water } & 0.60 \\
\hline P-2 & & & 0.50 \\
\hline $\mathrm{P}-3$ & & & 0.45 \\
\hline P-4 & & & 0.40 \\
\hline TP-1 & \multirow{4}{*}{ l } & \multirow{4}{*}{$\begin{array}{l}\text { TEMPO mixture } \\
\text { TEMPO: } 0.45 \mathrm{mmol} / \mathrm{g} \\
\mathrm{NaBr}: 3.158 \mathrm{mmol} / \mathrm{g} \\
\mathrm{NaOCl}: 2.6 \mathrm{mmol} / \mathrm{g}\end{array}$} & 0.50 \\
\hline TP-2 & & & 0.40 \\
\hline TP-3 & & & 0.30 \\
\hline TP-4 & & & 0.20 \\
\hline HCTP-1 & \multirow{5}{*}{$\begin{array}{c}\text { High consistency } \\
\underline{\text { TEMPO oxidation }} \\
\text { TEMPO: } 0.45 \mathrm{mmol} / \mathrm{g} \\
\mathrm{NaBr}: 3.158 \mathrm{mmol} / \mathrm{g} \\
\mathrm{NaOCl}: 3.81 \mathrm{mmol} / \mathrm{g}\end{array}$} & \multirow{5}{*}{ Water } & 1.00 \\
\hline HCTP-2 & & & 0.50 \\
\hline НCTP-3 & & & 0.40 \\
\hline НCTP-4 & & & 0.30 \\
\hline HCTP-5 & & & 0.25 \\
\hline BTP-1 & \multirow{3}{*}{$\begin{array}{l}\text { TEMPO oxidation }^{\mathrm{b}} \\
\text { TEMPO: } 0.45 \mathrm{mmol} / \mathrm{g}\end{array}$} & \multirow{3}{*}{ Water } & 1.00 \\
\hline BTP-2 & & & 0.50 \\
\hline ВTP-3 & & & $0.15^{\mathrm{d}}$ \\
\hline \multicolumn{4}{|c|}{${ }^{a}$ Conditions adapted to get a $25 \%$ final consistency } \\
\hline \multicolumn{4}{|c|}{${ }^{\mathrm{b}}$ Conditions determined by previous research (Myja et al., 2018) } \\
\hline \multicolumn{4}{|c|}{${ }^{\mathrm{c}}$ Mix conditions adapted to conserve $1 \mathrm{~L} / \mathrm{min}$ flow } \\
\hline${ }^{\mathrm{d}}$ Flow increa & pulp blocking betwe & & \\
\hline
\end{tabular}

\subsubsection{Pulp analysis}

On each pulp, in addition to the specific energy measured during the refining, the Canadian Standard Freeness (CSF), the weight-weighted (ww) fiber length and the length-weighted (lw) percent fines were measured. The CSF was determined according to the TAPPI T227 om-99 (1999) standard. Fiber length and 
percent fines were determined with a L\&W Fiber Tester Plus according to the TAPPI T232 cm-01 (2001) standard.

Pulps from primary chips refining were also screened with a MasterScreen Pulmac system according to the TAPPI T274 sp-08 (2013) method. Screen plate with $0.0100 \mathrm{~mm}$ (0.004 inch) slot sizes was used to retain only biggest shives of 3 grams of dry pulp per test.

The carboxylic groups content was also measured on pulps or shives, recovered after the Pulmac screening, with the Beatson method [14]. It consisted in a conductimetric titration with sodium hydroxide at 0,1 M. Before titration, pulps were protonated twice with hydrochloric acid at $0.1 \mathrm{M}$ for 45 minutes. After washing and filtration, the protonated pulp was dispersed in sodium chloride salted water at $10^{-3} \mathrm{M}$. Finally, $10 \mathrm{~mL}$ of $0.1 \mathrm{M}$ hydrochloric acid was added to the suspension just before titration in order to have the titration specific curve and so, determine the carboxylic group content. In a whole pulp, the fiber carboxylic group content could be calculated with the shive percent, pulp carboxylic group content and shive carboxylic group content according to the equation (1).

$$
F C G C=\frac{P C G C-S P * S C G C}{1-S P}
$$

With:

- FCGC: Fiber carboxylic group content (mmol/kg)

- PCGC: Pulp carboxylic group content (mmol/kg)

- SGCG: Shive carboxylic group content $(\mathrm{mmol} / \mathrm{kg})$

- SP: Shive percent $(\%)$

Each non-oxidized or oxidized pulp, with a carboxylic group content under $1500 \mathrm{mmol} / \mathrm{kg}$, which were obtained after a secondary refining were used to make paper sheets. Handsheets were prepared according to the TAPPI T205 sp-02 (2006) standard. On all handsheets, ISO brightness, tensile index and tear index were measured according to TAPPI T571 om-03 (2006) or TAPPI T220 sp-01 (2001) methods. On oxidized pulp with a carboxylic group content higher than $1500 \mathrm{mmol} / \mathrm{kg}$, a centrifugation was made at 15000 rotation per minute for 20 minutes with a Sorvall ST16 Centrifuge. This has allowed us to determine the nanofiber percent in the oxidized pulp. 


\subsubsection{Hydrogen peroxide pulp bleaching}

In order to evaluate pulp behavior to bleaching with or without TEMPO treatment, a hydrogen peroxide bleaching was performed on selected pulp. First, DTPA pretreatment were made on $25 \mathrm{~g}$ of dry pulp at $3 \%$ consistency, $60^{\circ} \mathrm{C}$, during 15 minutes with a $0.30 \%$ DTPA load. After pulp washing and filtration, the bleaching was performed at $12 \%$ consistency, $70^{\circ} \mathrm{C}$, during 3 hours with sodium silicate, sodium hydroxide and hydrogen peroxide respectively at 3.0\%, 3.7\% and 5.0\% loads. Finally, pulp brightness and yellowness (b*) were measured on 4 grams handsheets. These values were compared to initial pulp optical properties measured on 4 grams handsheets too.

\subsubsection{IKA dispersion}

To further investigate the refiner behavior for defibrillation and nanofiber production, nanofiber percent in pulps were compared to the same pulp dispersed by a colloid milling apparatus (MK 2000/4) from IKA Works, Inc.. Dispersion conditions were determined according to Loranger et al. [15] laboratory optimal conditions. The rotor-stator gap was fixed to $0.042 \mathrm{~mm}$, the consistency was at $2 \%$, the recycling flow rate at $200 \mathrm{~mL} / \mathrm{min}$ and the $\mathrm{pH}$ around 7. IKA energy consumption during the dispersion was noted to compare with refining specific energy.

\section{Results and discussion}

\subsection{Primary refining of softwood chips}

The comparison of $\mathrm{C} 1$ and $\mathrm{TC} 1$ results in Table 3 did not shown a significant effect when water was replaced by the TEMPO mixture in chips impregnation. Indeed, at the same disc gap, the refining specific energy was closely the same and only slight variation were observed on freeness, fiber length and fines and shives percent. The main difference appeared on the carboxylic content which is showing that the TEMPO reaction did occurred on chips, but the oxidation effect was too small to significantly impact the refining and fibers. A potential reason of the oxidation low effect were reaction time and fiber accessibility. Researches based on TEMPO oxidation of pulp $[10,11]$ had studied the reaction time in hours. In this experimentation, TEMPO mixture was applied on chips during only a few minutes from impregnation to refining then washing. The potential reaction time was clearly too small to get a significant chip oxidation. 
Table 3 Properties of pulps after primary refining

\begin{tabular}{|c|c|c|c|c|c|c|c|c|}
\hline \multirow{2}{*}{ Pulp } & Specific & \multirow{2}{*}{ energy } & Freeness & Fiber & Fines & \multicolumn{2}{|c|}{ Shives } & \multicolumn{3}{|c|}{ Carboxylic group content } \\
\cline { 6 - 10 } & & length (ww) & content (lw) & content & Pulp & Shive & Fiber $^{\text {a }}$ \\
\cline { 6 - 10 } & $\mathrm{MJ} / \mathrm{kg}$ & $\mathrm{mL}$ & $\mathrm{mm}$ & $\%$ & $\%$ & \multicolumn{3}{|c|}{$\mathrm{mmol} / \mathrm{kg}$} \\
\hline $\mathrm{C} 1$ & 2.27 & 715 & 2.21 & 61.0 & 24,1 & 120 & 41 & 145 \\
\hline $\mathrm{TC} 1$ & 2.43 & 702 & 2.25 & 61.8 & 27.1 & 220 & 45 & 285 \\
\hline BTC-1 & 1.13 & 425 & 1.11 & 69.5 & 47.5 & 545 & 89 & 958 \\
\hline BTC-2 & 2.19 & 297 & 1.21 & 71.0 & 40.9 & 605 & 69 & 977 \\
\hline BTC-3 & 4.27 & 217 & 1.62 & 64.3 & 21.2 & 675 & 58 & 841 \\
\hline
\end{tabular}

To further investigate the oxidation time on chips, dislocated softwood chips were treated with TEMPO system in batch for one hour. Pulp carboxylic group content values of BTC-1 (Table 3) was significantly higher than $\mathrm{C} 1$ or $\mathrm{TC} 1$ values. With this observation, it was possible to assess that the reaction time to produce $\mathrm{TC} 1$ pulp was much too short to observe any oxidation effect. However, the pulp carboxylic group content for BTC-1 (545 mmol/kg) was significantly lower than the carboxylic content calculated with model from Myja et al. [12] on thermomechanical pulp $(\approx 2000 \mathrm{mmol} / \mathrm{kg})$ with the same reaction conditions. Therefore, it was possible to affirm that fiber surface accessibility for reaction in chips had also a significant effect on TEMPO oxidation efficiency.

When BTC-1 and $\mathrm{C} 1$ or TC1 pulps are compare, it is possible to observe the oxidation effect on chips refining. These three pulps were refined with the same conditions but the specific energy leading to BTC-1 was significantly lower. According to Li et al. [16], chip properties could change the refining intensity. Therefore, the TEMPO oxidation, which is a surface treatment, has changed chips properties, inducing a decrease of refining intensity. Fiber length, which is not affected by TEMPO treatment according to Lianshan et al. [17], was smaller for BTC-1 compared to $\mathrm{C} 1$ and $\mathrm{TC} 1$ while fines and shives content increased. In addition, fiber carboxylic content was higher for BTC-1, thus showing that the refining mainly defibrillated small oxidized fibers of the chips surface and leave a high amount of non-oxidized shives. 
Decreasing disc gap in batch treated chip refining naturally increased the specific energy and decreased freeness and shives. Pulp carboxylic group content increased with the specific energy because of the increase of exposed surface. However, fiber carboxylic group content decreased induced by an increase of long non-oxidized fiber in pulp leading also to an increase of fiber length.

To conclude on chips treatment, the oxidation as only on small impact by chips impregnation mostly explained by the low reaction time. The batch reaction had significantly more impact but fiber accessibility in chips did not allowed a treatment as effective as in pulp oxidation. However, refining batch treated chips modify the properties of primary pulp produced compared to the refining of non-treated chips with the same refining conditions.

\subsection{Secondary refining of a primary pulp from softwood chips}

A secondary refining was made on $\mathrm{C} 1$ and $\mathrm{TC} 1$ pulps, leading respectively to $\mathrm{C} 2$ and $\mathrm{TC} 2$ pulps, to determine if the chips treatment had an effect on final secondary pulp or paper. On the Fig. 1, pulps properties (freeness, weight-weighted fiber length and percent fines) and paper physical properties (ISO brightness, tensile index and tear index) from $\mathrm{C} 1$ and $\mathrm{TC} 1$ refining were compared at several specific energy. Pulps properties evolution were globally the same for the two pulps, but at a same specific energy, freeness, fiber length and percent fines were a bit higher for TC2. These observations were the same that we have made on the primary pulp. Handsheets physical properties had also quite the same evolution. However, brightness and tensile index were lower for TC2 at a same specific energy. Freeness and tensile index variation from $\mathrm{C} 2$ to $\mathrm{TC} 2$ could be explained by a modification of the refining effect induced by a change in the fiber morphology. Indeed, Lianshan et al. [17] had observed an effect of the TEMPO oxidation on the fiber curl and kink index. The decrease in brightness could be explained by the TEMPO mixture $\mathrm{pH}$. During a TEMPO oxidation, the $\mathrm{pH}$ is usually controlled at 10.5 , but during the chips impregnation the $\mathrm{pH}$ could not be controlled, and the mixture was at an initial $\mathrm{pH}$ around 13.3. At this $\mathrm{pH}$, an alkaline darkening will most certainly occur and decrease the paper brightness. To further investigate this phenomenon, results from pulps C2-2 and TC2-3 hydrogen peroxide bleaching were reported in Table 4. 

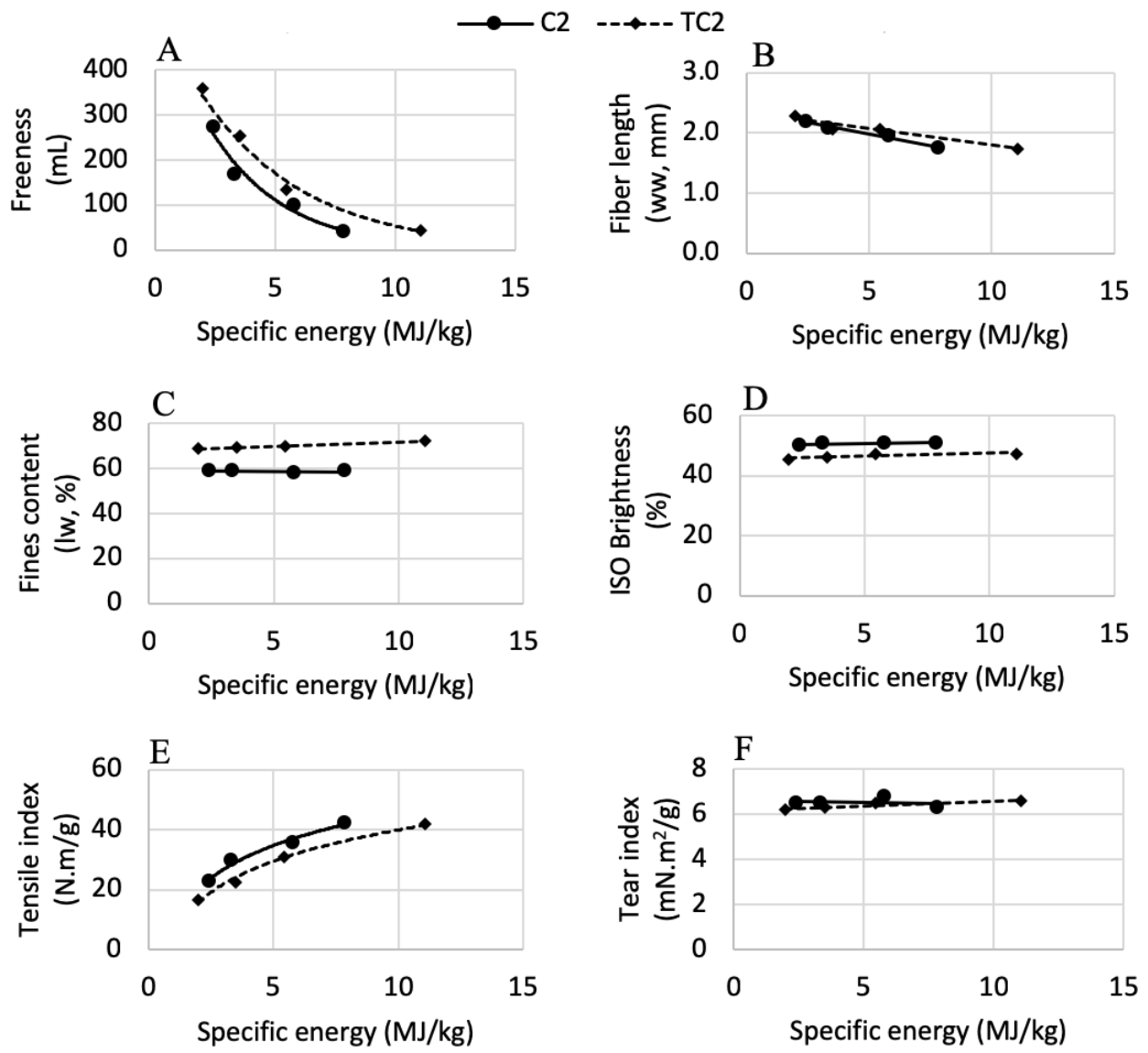

Fig. 1 Evolution of freeness (A), weight-weighted fiber length (B), length-weighted percent fines (C), ISO brightness (D), tensile index (E) and tear index (F) according specific energy used for the secondary refining of primary pulp of water impregnated (C2) or TEMPO impregnated (TC2) softwood chips

Table 4 Effect of hydrogen peroxide bleaching on optical properties of two secondary pulp from chips

\begin{tabular}{|c|c|c|c|c|}
\hline \multirow{2}{*}{ Pulp } & \multicolumn{2}{|c|}{ Before hydrogen peroxide bleaching } & \multicolumn{2}{c|}{ After hydrogen peroxide bleaching } \\
\cline { 2 - 5 } & ISO Brightness (\%) & Yellowness (b*) & ISO Brightness (\%) & Yellowness (b*) \\
\hline C2-2 & 51.8 & 13.3 & 72.2 & 11.3 \\
\hline TC2-3 & 47.2 & 14.2 & 61.8 & 14.7 \\
\hline
\end{tabular}

As seen on Fig. 1, brightness was higher for $\mathrm{C} 2$ pulp than TC2. In addition, yellowness increased with an impregnation of wood chips with TEMPO mixture probably induced by alkaline darkening. Same conditions hydrogen peroxide bleaching increased pulps brightness, but the brightness increased only by 
$14.6 \%$ for TC2-3 while an increase of $20.4 \%$ was observed for C2-2. Le Roux et al. [18] had already studied hydrogen peroxide bleaching of TEMPO oxidized pulp but on deinked pulp from newspaper and magazines. They observed a higher brightness for oxidized pulp after bleaching than on original pulp. According to the brightness and yellowness values observed for treated TMP in this study, an optimization of the hydrogen peroxide bleaching must be done to observe a potential improvement in paper brightness. Finally, impregnation of softwood chips with TEMPO mixture had an impact on optical properties of secondary pulp handsheets.

\subsection{Secondary refining of a commercial softwood primary pulp}

Carboxylic group content of usual refined pulp (P), pulp refined with TEMPO mixture (TP) and pulp pretreated with TEMPO at high consistency (HCTP) were respectively around 90, 335 and 250 $\mathrm{mmol} / \mathrm{kg}$. For this reason, the same analysis as the previous secondary pulp was made. For batch treated pulps (BTP), carboxylic group contents were higher than $1800 \mathrm{mmol} / \mathrm{kg}$. Therefore, in addition to specific energy consumption and carboxylic group content measurement, the nanofiber percent in pulp was determined. Fig. 2 show P, TP and HCTP pulps and handsheets properties.

Measure of the freeness directly show a treatment effect on pulp refining. Indeed, much lower energy was needed to decrease pulp freeness for high consistency treated pulp compared to pulp refined with TEMPO mixture and even more compared to pulp refined with water only. This could be explained by the small difference in fiber length or percent fines but also by the addition of carboxylic groups at fiber surface which improve interfiber bonding as shown by Ma et al. [19]. For handsheets brightness, the same observation as previously could be made. The TEMPO treatment significantly decreased the brightness. Furthermore, the lowest brightness was achieved for TP pulps. This situation is clearly indicating that a high alkaline darkening occurred in the few minutes from the refiner until the pulp washing. About handsheets mechanical resistances, TEMPO treatment inside the refiner did not seems to have significant effect on tensile resistance compared to usual pulp refining. However, the same treatment significantly decrease the tear index. Ma et al. [20] had observed an important decrease in fiber strength induced by TEMPO oxidation on thermomechanical pulp, which is explaining the significant decrease in tear index. According to tensile and tear resistance observed, the TEMPO treatment inside the refiner was more harmful than beneficial. On the other side, the high consistency treatment has enable a significant specific energy decrease for a given tensile 
index. Indeed, in order to get a tensile index of $40 \mathrm{~N} \cdot \mathrm{m} / \mathrm{g}$, around $2.18 \mathrm{MJ} / \mathrm{kg}$ was needed to refine HCTP while around $4.76 \mathrm{MJ} / \mathrm{kg}$ was needed for untreated pulp. It represented more than a half energy economy. However, as for the TP pulp, a high decrease was observed for the tear index revealing a huge effect on fibers intrinsic strength.


Fig. 2 Evolution of freeness (A), weight-weighted fiber length (B), length-weighted percent fines (C), ISO brightness (D), tensile index (E) and tear index (F) according specific energy used for the secondary refining of softwood thermomechanical untreated pulp (P), pulp treated with TEMPO in the refiner (TP) and pulp treated with TEMPO at high consistency (HCTP)

The brightness and yellowness of pulps before and after hydrogen peroxide bleaching presented same evolution as for secondary chips refining. In the Table 5, the highest brightness increase was measured for the untreated pulp. Furthermore, yellowness was significantly higher for treated pulps and still increase with the hydrogen peroxide bleaching. These results clearly demonstrated that studied TEMPO treatment induced an alkaline darkening which could not be reversed with a usual hydrogen peroxide procedure. 
Table 5 Effect of hydrogen peroxide bleaching on optical properties of three secondary pulp from softwood thermomechanical pulp

\begin{tabular}{|c|c|c|c|c|}
\hline \multirow{2}{*}{ Pulp } & \multicolumn{2}{|c|}{ Before hydrogen peroxide bleaching } & \multicolumn{2}{c|}{ After hydrogen peroxide bleaching } \\
\cline { 2 - 5 } & ISO Brightness (\%) & Yellowness (b*) & ISO Brightness (\%) & Yellowness (b*) \\
\hline P-3 & 55.3 & 13.0 & 75.2 & 11.0 \\
\hline TP-4 & 30.8 & 21.4 & 43.8 & 24.9 \\
\hline HCTP-5 & 38.1 & 17.3 & 52.1 & 19.8 \\
\hline
\end{tabular}

The batch treated pulp (BTP) presented a carboxylic group content higher than $1500 \mathrm{mmol} / \mathrm{kg}$ and according to Le Roux et al. [21], pulp containing a high carboxylic group content could not be used directly to make paper. However, highly oxidized pulp is interesting for nanofiber production [10]. For this reason, the refining was studied as a nanofiber production step. First, decreasing the disc gap had the effect of increasing pulp carboxylic group content as observed in Table 6. In addition, the same disc gap evolution also induced an increase of nanofiber amount in the pulp, which could explain the carboxylic group content modification with a higher surface exposition. The comparison of the refiner effect and the other dispersion setup used in the laboratory (IKA process), show a great efficiency of the refiner used as a disperser. Indeed, a higher amount of nanofiber could be produced with significantly lower specific energy. Tejado et al. [22] had also studied the energy requirement to produce nanofibers with mechanical dispersion. However, they used cellulose oxidized with periodate and chlorite which increased the carboxylic group content but also promoted fibers depolymerization, thus facilitating the disintegration. To produced $20 \%$ of nanofiber, with a pulp containing $2000 \mathrm{mmol} / \mathrm{kg}$ of carboxylic group, around $2.58 \mathrm{MJ} / \mathrm{kg}$ was needed. It also put forward the high refiner efficiency to produce nanofibers, which had other benefits as low dispersion time or continuous mode. 
Table 6 Carboxylic group content and nanofiber percent in highly oxidized pulp refined at different specific energy compared to a lab scale dispersion

\begin{tabular}{|c|c|c|c|}
\hline \multirow{2}{*}{ Pulp } & Specific energy & Pulp carboxylic group content & Nanofiber percent \\
\cline { 2 - 4 } & $\mathrm{MJ} / \mathrm{kg}$ & $\mathrm{mmol} / \mathrm{kg}$ & $\%$ \\
\hline BTP-1 & 0.63 & 1840 & 12.3 \\
\hline BTP-2 & 3.21 & 2005 & 23.8 \\
\hline BTP-3 & 4.80 & 2095 & 27.2 \\
\hline BTP-IKA & 57.11 & 1975 & 19.9 \\
\hline
\end{tabular}

\section{Conclusions}

According to the results, followed conclusions could have been made:

- $\quad$ Chips impregnation with TEMPO mixture had mostly harmful effect on primary and secondary pulp properties, which is therefore not recommended.

- Chips batch oxidation was significantly effective and change refining effets. Further investigation is needed to determine if any beneficial effects are achieved.

- $\quad$ TEMPO oxidation on pulp presented better results when the treatment was made at high consistency and involved a high refining energy decrease. However, tear strength was negatively impacted by the treatment.

- $\quad$ TEMPO treatment on chips or pulp harshly affected the optical properties. Alkaline darkening occurred during the treatment could not be removed with usual hydrogen peroxide bleaching. A control of the $\mathrm{pH}$ during TEMPO treatments or an optimization of the hydrogen peroxide bleaching should be investigated to see if better optical properties can be obtained.

- $\quad$ Refiner appeared to be a very efficiency dispersion system to produce nanofibers from high oxidized pulps at low energy consumption compared to other systems.

\section{Acknowledgements}

Funding: This work was supported by Natural Sciences and Engineering Research Council of Canada (NSERC). 


\section{References}

[1] A. E. J. d. Nooy, A. C., Besemer, H. v. Bekkum, Highly selective nitroxyl radical-mediated oxidation of primary alcohol groups in water-soluble glucans, Carbohydr. Res. 269 (1994) 89-98. https://doi.org/10.1002/recl.19941130307

[2] G. Pierre, C. Punta, C. Delattre, L. Melone, P. Dubessay, A. Fiorati, P. Michaud, TEMPO-mediated oxidation of polysaccharides: an ongoing story, Carbohydr. Polym. 165 (2017) 71-85. https://doi.org/10.1016/j.carbpol.2017.02.028

[3] P. S. Chang, J. F. Robyt, (1996). Oxidation of primary alcohol groups of naturally occuring polysaccharides with 2,2,6,6-tetramethyl-1-piperidine oxoammonium ion, Carbohydr. Chem. 15 (1996) 819-830. https://doi.org/10.1080/07328309608005694

[4] P. Ma, H. Zhai, Selective TEMPO-mediated oxidation of thermomechanical pulp, BioResources 8 (2013) 4396-4405. https://doi.org/10.15376/biores.8.334396-4405

[5] B. Puangsin, Q. Yang, T. Saito, A. Isogai, Comparative characterization of TEMPO-oxidized cellulose nanofibril films prepared from non-wood resources, Int. J. Biol. Macromol. 59 (2013) 208-213. https://doi.org/10.1016/j.ijbiomac.2013.04.016

[6] K.-L. Law, C. Daneault, R. Guimond, TEMPO-mediated oxidation of softwood thermomechanical pulp long fibers, Cell. Chem. Technol. 42 (2008) 31-36.

[7] Y. Zhou, T. Saito, L. Bergstrom, A. Isogai, Acid-Free Preparation of Cellulose Nanocrystals by TEMPO Oxidation and Subsequent Cavitation, Biomacromolecules 19 (2018) 633-639. https://doi.org/10.1021/acs.biomac.7b01730

[8] B. Bideau, L. Cherpozat, E. Loranger, C. Daneault, Conductive nanocomposites based on TEMPOoxidized cellulose and poly(N-3-aminopropylpyrrole-co-pyrrole), Ind. Crops Prod. 93 (2016) 136141.

[9] N. Lin, A. Dufresne, Nanocellulose in biomedicine: Current status and future prospect, Eur. Polym. J. 59 (2014) 302-325. https://doi.org/10.1016/j.eurpolymj.2014.07.025

[10] T. Saito, A. Isogai, TEMPO-mediated Oxidation of Native Cellulose. The Effect of Oxidation Conditions on Chemical and Crystal Structures of the Water-Insoluble Fractions, Biomacromolecules 5 (2004) 1983-1989. https://doi.org/10.1021/bm0497769 
[11] S. Iwamoto, W. Kai, T. Isogai, T. Saito, A. Isogai, T. Iwata, Comparison study of TEMPO-analogous compounds on oxidation efficiency of wood cellulose for preparation of cellulose nanofibrils, Polym. Degrad. Stab. 95 (2010) 1394-1398. https://doi.org/10.1016/j.polymdegradstab.2010.01.017

[12] D. Myja, E. Loranger, R. Lanouette, TEMPO mediated oxidation optimization on thermomechanical pulp for paper reinforcement and nanomaterial film production, BioResources 13 (2018) 4075-7092. https://doi.org/1015376/biores.13.2.4075-4092

[13] M. Paquin, E. Loranger, V. Hannaux, B. Chabot, C. Daneault, The use of Weissler method for scale-up a Kraft pulp oxidation by TEMPO-mediated system from a batch mode to a continuous flow-through $\begin{array}{lllll}\text { sonoreactor, } & \text { Ultrason. } & \text { Sonochem. } & 20 & \text { (2013) }\end{array}$ https://doi.org/10.1016/j.ultsonch.2012.08.007

[14] R. P. Beatson, Determination of sulfonate groups and total sulfur, in: Y. Lin, D. W. Dence (Eds), Methods in Lignin Chemistry, Springer Series in Wood Science, Berlin, 1992, pp. 473-484.

[15] E. Loranger, A.-O. Piché, C. Daneault, Influence of High Shear Dispersion on the Production of Cellulose Nanofibers by Ultrasound-Assisted TEMPO-Oxidation of Kraft Pulp, Nanomaterials 2 (2012) 286-297. https://doi.org/10.3390/nano2030286

[16] B. Li, H. Li, Q. Zha, R. Bandekar, A. Alsaggaf, Y. Ni, Review: Effects of wood quality and refining process on TMP pulp and paper quality, BioResources $6 \quad$ (2011) 3569-3584. https://doi.org/10.15376/biores.6.3.3569-3584

[17] M. Lianshan, K.-N. Law, C. Daneault, F. Brouillette, Effects of Carbonyl Content on the Characteristics of TMP Long Fibers, Ind. Eng. Chem. Res. 47 (2018) 3809-3812. https://doi.org/10.1021/ie071274z

[18] J. Le Roux, C. Daneault, B. Chabot, Tempo-Mediated Oxidation to improve deinked pulp quality, Pulp Pap. Canada 111 (2010) 18-22.

[19] P. Ma, K.-N. Law, C. Daneault, H. Zhai, Influence of oxidation and cationization on properties of TMP fibers, Cell. Chem. Technol. 45 (2011) 389-395.

[20] P. Ma, K.-N. Law, C. Daneault, Influence of oxidation on intrinsic fiber strength,” Cell, Chem. Technol. 43 (2009) 387-392.

[21] J. Le Roux, C. Daneault, B. Chabot, Acidic groups in TMP oxidized fibres by TEMPO to improve paper strength properties, Pulp Pap. Canada 107 (2006) 39-41. 
[22] A. Tejado, Md.N. Alam, M. Antal, H. Yang, T.G.M. van de Ven, "Energy requirements for disintegration of cellulose fibers into cellulose nanofibers, Cellulose 19 (2012) 831-842. https://doi.org/10.1007/s10570-012-9694-4 